\title{
REAÇÕES EMOCIONAIS DA MULHER NO PUERPÉRIO
}

Isilia Aparecida Silva*

SILVA, I.A. Reaçdes emocionais da mulher no puerpério. Rev. Esc. Enf. USP, Såo Paulo, 22(2):237-246, ago. 1988.

A autora procurou obter, através de declarações de enfermeiras, informaçào sobre se estas conseguem identificar manifestą̧öes de comportamento de puérperas que evidenciam reaçóes emocionais e se as mesmas se julgam preparadas para atender adequadamente as puérperas, considerando tanto os aspectos fisicos quanto os emocionais.

UNITERMOS. Enfermagem obstétrica. Puerpério.

\section{INTRODUÇĀO}

Gravidez, parto e puerpério continuam sendo alvo de muitos estudos na tentativa de elucidar pontos ainda não desvendados.

Para a sociedade, de modo geral, o nascimento de uma criança é motivo de grande alegria e comemoraçōes. No entanto, para a mulher que se torna mãe, este periodo pode ser marcado por ansiedades e preocupaçðes, principalmente quando se trata do primogênito.

MALDONADO ${ }^{\mathbb{R}}$ afirma que a gravidez constitui uma situação crítica, implicando em maior vulnerabilidade emocional da mulher e desorganização do seu padrão de vida, devidas a inúmeras modificaçoes fisiológicas e em estados emocionais peculiares, que justificam a presença de certo grau de ansiedade.

DEUTSCH' $\mathrm{H}^{5}$ considera que os temores e as preocupaçסes gerados durante a gravidez podem ser sanados com o parto, ou podem continuar, sob forma de excessiva ansiedade que gira em torno do filho; neste caso, as apreensð̃es da gestante não terminam com o parto. Após o parto, inicia-se o puerpério, que é um novo período de adaptaçðes psíquicas e fisiológicas, com reaçðes conscientes e inconscientes.

Muito se sabe sobre as alteraçðes fisiológicas e anatômicas, pelas quais passa a mulher no puerpério, havendo inúmeras definiçðes sobre este periodo nos textos que tratam da assistência à mulher no ciclo grávido puerperal.

Lamentavelmente, a evolução científica na área da obstetrícia concentrou-se mais nos progressos técnicos que permitem detectar precocemente os desvios clínicos do processo reprodutivo da mulher. As mudanças emocionais que se produzem na gestante, bem como o significado que pode ter o parto, para a mesma, não tem sido suficientemente investigada (CANELLA ${ }^{3}$ ).

Segundo RUBIN'3, a puérpera, após o parto, experimenta uma fase de euforia e excitação durante a qual pretende falar a todos a respeito de sua experiência e de seu

- Enfermeira. Mestre em Enfermagem. Professor Assistente do Departamento de Enfermagem Materno-Infantil e Psiquiátrica da Escola de Enfermagem da USP - disciplina Enfermagem Obstétrica, Neonatal e Ginecológica. 
bebê. A seguir, nos primeiros dias após o parto, o comportamento da puérpera caracteriza-se por passividade e dependência no qual exprime muito mais as suas necessidades que as de seu filho. Esta é a fase de instalação ou reabastecimento do puerpério e que dura cerca de 2 a 3 dias, na qual a puérpera deverá ter suas necessidades satisfeitas a fim de se tornar capaz de cuidar de seu filho.

Progressivamente, a puérpera passa de estado de dependência para um de independência e autonomia - fase de participação do puérpério, e que se desenvolve até o 10. dia pós-parto. Esta fase transcorre em um clima de forte desejo da mãe em cuidar de si mesma e de seu filho; no entanto, quase sempre está presente um forte elemento de ansiedade, causado pela insegurança sobre a sua capacidade de cuidar da criança, pelo fato de ter de assumir essa responsabilidade e pelos sentimentos ambivalentes em relação ao bebê, somados ainda a uma série de outros fatores.

Podemos observar que a fase de instalação do puerpério se dá justamente no período em que a puérpera está internada na maternidade. É nesta fase que as mães se mostram dependentes, aceitando com gratidão tudo o que lhes é oferecido. Embora as puérperas sejam bastante receptivas para o aprendizado, INGALLS \& SALERNO $^{6}$ comentam que o período de hospitalização não é suficiente para que elas assimilem sua nova condição de mãe e, principalmente, tenham segurança e estabilidade no novo papel.

A naturalidade com que os que assistem e rodeiam a mãe encaram a maternidade não pode, porém, diminuir a importância dos cuidados que devem ses prestados a esta mulher que está se adaptando física e emocionalmente a uma experiência nova $e$ a uma nova estrutura familiar.

O puerpério não pode ser visto como um evento isolado na vida da mulher; esta deve ser compreendida como uma pessoa sob o impacto de grande mudança em sua existência (SHEEHAN ${ }^{14}$ ).

Preocupam-nos, pois, intensamente, as reaçðes emocionais da puérpera, porque estas indicam de algum modo, necessidades básicas não satisfeitas.

A enfermeira deve estar consciente de que é necessário haver melhor compreensão das manifestaçðes de reaçðes emocionais da puérpera e que esta compreensão deve ser considerada tão importante quanto os cuidados físicos. Os fatores emocionais precisam ser levados em consideração, pois, segundo BEINSTEIN², a assistência inadequada pode dar origem à depressão puerperal.

Sendo assim, a mãe deverá ser objeto de cuidados adequados à sua individualidade, que não só lhe proporcionem bem-estar fisico, mas também, que tenha suas necessidades emocionais satisfeitas.

A enfermeira, ao utilizar continuamente suas habilidades de observação e comunicação, poderá identificar reaçōes emocionais inerentes à puérpera. Cabe a ela, enfermeira, uma visão e atuação mais amplas e criativas dos cuidados prestados à puérpera. A avaliação da situação e a correta intervenção da enfermeira serão de grande valor para a mãe.

A enfermeira poderá ajudar a puérpera de maneira mais efetiva se souber reconhecer e interpretar o comportamento materno.

Diante dos fatos aqui considerados, foram objetivos deste estudo:

- Verificar se as enfermeiras são capazes de reconhecer reações emocionais de puérperas, a partir de suas manifestaçðes de comportamento; 
- Verificar se as enfermeiras se julgam preparadas para dar atendimento global às puérperas, considerando não só os aspectos físicos como, também, os emocionais;

- Verificar se as enfermeiras são capazes de enumerar as açòes de enfermagem que såo necessárias para assistência adequada às puérperas.

\section{METODOLOGIA}

\section{População e local}

O estudo foi realizado com enfermeiras * que assistem puérperas em hospitais e maternidades do Municipio de São Paulo.

Foram sorteados dez (10) hospitais e maternidades de um lista de 92 instituiçōes, fornecida pelo Serviço de Registro e Cadastro da Coordenadoria de Assistência Hospitalar do Estado de São Paulo.

Nestes hospitais e maternidades foram selecionadas as enfermeiras que assistem às puérperas prestando às mesmas cuidado direto ou indireto.

Foram considerados, para este estudo, os conceitos de cuidado direto e indireto de KURCGANT':

"Cuidado direto: quando a enfermeira ou obstetriz executa atividades de enfermagem com o paciente, para o paciente, sem o intermédio de outras pessoas e quando o efeito dessas atividades é sentido de forma direta e imediata pelo paciente".

"Cuidado indireto: quando a enfermeira ou obstetriz assite ao paciente por intermédio de outros elementos da equipe de enfermagem, e o efeito das suas açoes é sentido de forma indireta e mediata pelo paciente".

\section{Instrumento de coleta de dados}

Foi utilizado para coleta de dados o formulário de questoes abertas, constante de duas partes. A primeira contém questões sobre dados gerais da enfermeira. A segunda consta de perguntas às enfermeiras sobre:

- manifestações de comportamento que evidenciam reaçðes emocionais de puérperas;

- preparo do profissional para atender às puérperas no que diz respeito às reaçðes emocionais;

- como assitir adequadamente a puérpera.

\section{Coleta de dados}

Para coleta de dados foi utilizada a técnica de entrevista, realizada no hospital, em local que permitiu manter a privatividade. O formulário foi preenchido durante a entrevista.

\footnotetext{
* Na categoria de enfermeiras foram incluidas as obstetrizes (com ou sem complementaçào do curso de Enfermagem) e as enfermeiras com habilitação ou especializaçăo em Enfermagem Obstétrica.
} 


\section{RESULTADOS E COMENTÁRIOS}

Dados gerais das enfermeiras entrevistadas

Fizeram parte deste estudo $46(100,0 \%)$ profissionais, sendo que $34(73,9 \%)$ eram enfermeiras obstétricas*, $11(23,9 \%)$ eram obstetrizes e $1(2,2 \%)$ era enfermeira.

Nesta amostra constatamos que as $11(23,9 \%)$ obstetrizes eståo trabalhando em períodos de tempo que variam de 12 a 26 anos e as enfermeiras de 0 a 12 anos.

Quanto ao tipo de cuidado que prestam às puérperas vemos pela Tabela 1 que $39(84,8 \%)$ profissionais prestam cuidado direto.

As manifestações de comportamento que evidenciam reaçōes emocionais de puérperas, relatadas pelas enfermeiras nos três periodos do puerpério, determinados para este estudo, foram agrupadas e são apresentadas nas Tabelas 2,3 e 4.

TABELA 1

DISTRIBUIÇÃO DAS ENFERMEIRAS QUANTO AO TIPO DE CUIDADO QUE PRESTAM À PUERRERA.

\begin{tabular}{lcc}
\hline \hline & & Enfermeiras \\
Tipo de Cuidado & No & $\%$ \\
\hline Direto & 39 & 84,8 \\
Indireto & 07 & 15,2 \\
\hline TOTAL & 46 & $100,0 \%$ \\
\hline
\end{tabular}

TABELA 2

DISTRIBUIÇĀO DAS MANIFESTAÇOES DE COMPORTAMENTO QUE EVIDENCIAM REAÇOES EMOCIONAIS DE PUERPERAS NO PERIODO DE ZERO A DUAS HORAS DE PÓS-PARTO, RELATADAS POR ENFERMEIRAS.

\begin{tabular}{llc}
\hline \hline Manifestạ̧ós & No & $\%$ \\
\hline Preocupação em relação à integridade física do filho & 34 & 38,1 \\
Alegria & 15 & 16,9 \\
Emoção pelo nascimento do filho & 11 & 12,3 \\
Alívio & 09 & 10,3 \\
Indiferença & 06 & 6,8 \\
Medo & 05 & 5,6 \\
Rejeição & 03 & 3,4 \\
Ansiedade por separar-se do filho & 02 & 2,3 \\
Aceitação do filho & 02 & 2,3 \\
Preocupaç̧o com o sexo do fitho & 01 & 1,1 \\
Preocupaçร̃o com os filhos que deixou em casa & 01 & 1,1 \\
\hline TOTAL & $89^{* *}$ & 100,0 \\
\hline
\end{tabular}

* Este número se deve ao fato das enfermeiras terem dado mais de uma resposta.

* Enfermeiras que concluíram programas de Habilitaçăo ou Especialização em Enfermagem Obstétrica. 
No periodo de zero a duas $h$. aparecc, no relato das enfermeiras, como característica predominante, a preocupação da mãe com a integridade física do recém-nascido. Esta foi mencionada $34(38,1 \%)$ vezes. As enfermeiras referem que, em geral, segue-se uma demonstração de alegria e de emoção pelo nascimento da criança. $\mathrm{Na}$ Tabela 2, estes foram citados $15(16,9 \%)$ e $11(12,3 \%)$ vezes respectivamente.

Neste periodo foi citado também o medo pelo seu próprio bem-estar físico 5 $(5,6 \%)$, havendo preocupação com hemorragia e manipulação do corpo. Comparando a preocupação da mãe pela integridade física do recém-nascido, podemos supor que as mães nestas primeiras horas preocupam -se muito mais com o filho do que com elas próprias.

Podemos observar, ainda, na Tabela 2, que as màes podem demonstrar indirerença ou rejeição pelo filho, manifestaçðes citadas $6(6,8 \%)$ e $3(3,4 \%)$ vezes respectivamente. Embora este comportamento não tenha sido predominante, pensamos ser muito importante a atenção a ser dirigida à mãe para estas manifestaçठes e o pronto atendimento pelo profissional, no sentido de identificar as causas de tais reaçðes.

\section{TABELA 3}

DISTRIBUIÇÃO DAS MANIFESTAÇOEES DE COMPORTAMENTO QUE EVIDENCIAM REAÇOES EMOCIONAIS DE PUERPERAS NO PERIODO DE 2 A 72 HORAS DE POS-PARTO, RELATADAS POR ENFERMEIRAS.

\begin{tabular}{|c|c|c|}
\hline Manif estaçoes & Nọ & $\%$ \\
\hline Expressam preocupação com amamentaçāo & 30 & 21,1 \\
\hline Apresentam labilidade de humor & 19 & 13,4 \\
\hline Demonstram interesse em cuidar do filho só após o 19 dia & 16 & 11,2 \\
\hline Expressam desejo de descansar no 19 dia & 14 & 9,9 \\
\hline Demonstram preocupação com a integridade física do filho & 10 & 7,1 \\
\hline Querem ser o centro de atenção & 8 & 5,7 \\
\hline Demonstram desejo de ficar com o filho, mas não em cuidar do mesmo & 8 & 5,7 \\
\hline Denotam desinteresse em cuidar do filho & 7 & 4,9 \\
\hline Manifestam-se dependentes da equipe de enfermagem & 7 & 4,9 \\
\hline Demonstram preocupaçāo com a estética & 5 & 3,5 \\
\hline Referem medo de cuidar do fitho & 3 & 2,1 \\
\hline Denotam diminuição da ansiedade com o passar dos dias & 3 & 2,1 \\
\hline Expressam necessidade de verbalizar a experiência do parto & 3 & 2,1 \\
\hline Demonstram interesse até o dia da alta & 2 & 1,4 \\
\hline Expressam interesse imediato em amamentar & 1 & 0,7 \\
\hline Apresentam-se alegres e comunicativas & $i$ & 0.7 \\
\hline Apresentam ansiedade em relação ao controle da natalidade & 1 & 0,7 \\
\hline Referem ansiedade sobre o reinício das atividades sexuais & 1 & 0,7 \\
\hline Dão pouca importância à estética & 1 & 0.7 \\
\hline Demonstram interesse em amamentar, mas não em cuidar do filho & 1 & 0,7 \\
\hline Expressam ambivalência em relação ao filho & 1 & 0,7 \\
\hline TOTAL & $142 *$ & 100,0 \\
\hline
\end{tabular}

* Este número se deve ao fato das enfermeiras terem dado majs de uma resposta.

A caracteristica mais evidente no período de 2 a 72 horas do puerpério é a "preocupação com a amamentaçào" que foi citada $30(21,1 \%)$ vezes. Em geral as puérperas expressam esta preocupação relacionando-a principalmente com a capacidade para amamentar e a quantidade de leite. 
Este é um fator importante a ser considerado; como afirma WIEDEMBACH ${ }^{15}$, $o$ aleitamento está intimamente ligado a todo o processo reprodutivo. A resposta às necessidades de alimentação do recém-nascido depende sobremaneira do estado físico, mental e emocional da mãe, tanto quanto do desenvolvimento, condição e capacidade da mama de prover o leite.

Produzir o leite não é uma função exclusiva da mama, mas é uma função de todo o corpo da mulher, no qual a mama faz meramente a última parte do trabalho (NAISH ${ }^{10}$ apud). Podemos, assim, concluir que o sucesso da amamentação ou o fato da mãe se sentir capaz de amamentar depende muito de fatores externos de orientação, encorajamento, paciência e tranqüilidade.

Houve $7(4,9 \%)$ citaçðes de mães que não se interessam em amamentar seu filho. No entanto não foi relatado pelas respondentes o motivo pelo qual este desinteresse ocorre.

Observamos ainda, na Tabela 3, $19(13,4 \%)$ citaçðes referentes à labilidade de humor, assim denominada pelas enfermeiras quando se referiam à instabilidade emocional das puérperas. Descrevem as mães como emotivas, sensiveis, deprimidas e irritadas, chegando mesmo a apresentar agressividade. Este fato é corroborado pelo estudo de RUBIN ${ }^{12}$, quando comenta que nos primeiros dias a puérpera apresenta rápidas e freqüentes mudanças de humor, até adquirir equilíbrio emocional, o que só acontece por volta de 10 a 15 dias de pós-parto.

Os profissionais, ao comentarem a labilidade de humor da puérpera, tentaram explicá-lo como sendo decorrente do desconforto gerado pelas dores da episiorrafia ou da cicatriz cirúrgica, no caso de cesárea, distensão abdominal, mamas ingurgitadas ou mamilo dolorido.

Embora não tenhamos conhecimento de estudos que sirvam de base, nossa experiência atenta para o fato de que o período em que a puérpera se encontra internada é de grande agitação pelo número de visitas de amigos e parentes, o que prejudica, na maioria das vezes, o repouso da mãe, o desenvolvimento da interação mãe-filho-pai contribuindo para a irritação que a puérpera apresenta nesta fase.

Chama a atenção, ainda, no relato das enfermeiras (TABELA 3) a demonstração de interesse da mãe em cuidar do recém-nascido só após o primeiro dia do pós-parto, fato citado $16(11,2 \%)$ vezes. Esta citação está diretamente ligada à necessidade que a puérpera expressa de descansar no primeiro dia, mencionada 14 $(9,9 \%)$ vezes.

A citação "querem ser o centro das atençðes" e "manifestam-se dependentes da equipe de enfermagem" foram observadas $8(5,7 \%)$ e $7(4,9 \%)$ vezes respectivamente.

Estas citaçסes podem ser explicadas pelos estudos de BECKER' e de RUBIN'2, nos quais dizem que, neste periodo, a puérpera revela-se "faminta" de sono, comi$\mathrm{da}$, conforto e atenção por parte de todos que a rodeiam, para certificar-se de sua aceitação e da de seu filho pela família e grupo de amigos. É nesta fase uma preocupação importante para a puérpera a normalização das funçסes de seu organismo, dentre elas as eliminaçðes e a locomoção. É importante que ela se sinta capaz de cuidar de si mesma e de atender às suas proprias necessidades, a fim de poder atender adequadamente as necessidades do recém-nascido.

Para comentar as respostas da questão referente ao $3^{\circ}$. periodo, algumas consideraçðes merecem destaque.

Nos hospitais onde o estudo foi realizado as puérperas recebem alta hospitalar com 72 horas; apenas as puérperas que apresentam algum tipo de patologia perma- 
necem por mais tempo. Assim, da população de profissionais do estudo, $41(89,1 \%)$ enfermeiras não puderam responder a quesıão n: 3 do Anexo por alegarem não ter experiência alguma com puérperas no periodo que segue as 72 horas. As $5(10,9 \%)$ enfermeiras que responderam à questảo têm experiência neste periodo, por atenderem puérperas fora do ambiente hospitalar, no domicilio e em curso de orientação para gestantes e puérperas. Estas enfermeiras descrevem as manifestaçðes de reaçðes emocionais que estão distribuídas na Tabela 4.

\section{TABELA 4}

DISTRIBUIÇĀO DAS MANIFESTAÇOES DE COMPORTAMENTO QUE EVIDENCIAM REAÇOEES EMOCIONAIS DE PUERPERAS NO PERIODO APÓS 72 HORAS, RELATADAS PELAS 5 ENFERMEIRAS DO ESTUDO.

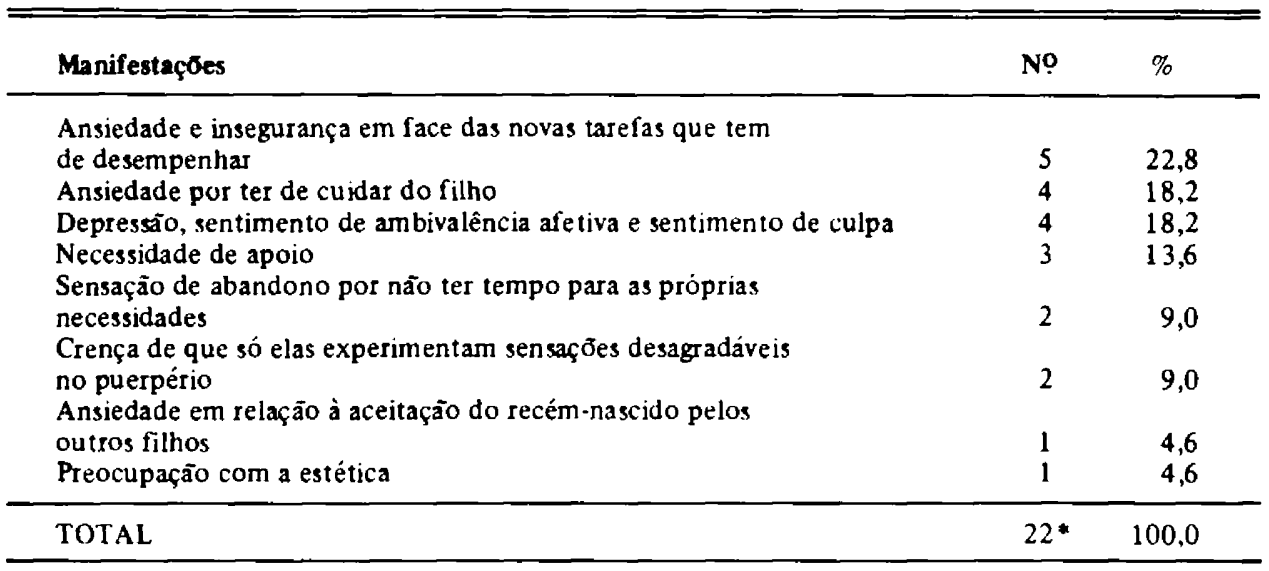

* Este número se deve ao fato das enfermeiras terem dado mais de uma resposta.

As enfermeiras foram unânimes ao descrever a puérpera com forte sentimento de ansiedade e insegurança, $5(22,8 \%)$ das citaçāo. SHEEHAN ${ }^{14}$, em relação a este fato, comenta que a màe muda o papel de dependência passiva que assume durante a hospitalização, pois, muito rapidamente deve preparar-se para assumir as responsabilidades do lar, por ocasião da alta.

Foi citado $4(18,2 \%)$ vezes que as puérperas, neste periodo, apresentam sentimento de ansiedade por ter de cuidar do recém-nascido e $4(18,2 \%)$, que as pessoas expressam ambivalência afetiva e sentimentos de culpa enı relação ao recém-nascido.

A depressāo da mãe no puerpério tem sido atribuida a mudanças psicológicas maciças após o parto, quando o maior falor envolvido é o fato da màe, aos poucos, tomar consciencia da enorme responsabilidade que tem para com a criança. Contribui para este sentimento de depressào a alençào transferida dela para o recénı-nascido, quando passa a ser questionada e responsabilizada pelo bem-estar deste (BECKER').

Houve $3(13,6 \%)$ afirmaçōes de que nesta fase a puérpera sente necessidade de apoio e $2(9,0 \%)$ de que ela se sente abandonada por nào ter tempo para o atendimento de suas próprias necessidades, uma vez que despende muita energia e tempo na execução de tarefas domésticas e nos cuidados com o filho. 
A preocupaçăo da puérpera com a estética foi citada uma única vez $(4,6 \%)$. RUBIN $^{13}$ e MERCER 4 comentam o fato de que a puérpera espera ansiosamente que seu corpo volte às medidas originais pré-gestacionais; como este é um processo lento, torna-se um fator de ansiedade.

Quanto ao preparo das enfermeiras para darem atendimento adequado às puérperas com as manifestaçoes de comportamento descritas, $41(89,1 \%$ ) enfermeiras responderam que se julgam preparadas e $5(10,9 \%)$ responderam que não.

Chama a atenção, entretanto, o fato de as enfermeiras que responderam negativamente não descreverem o que poderia ser feito nesse sentido para ajudá-las; elas apenas justificaram-se, alegando que o atendimento adequado não é possivel por falta de tempo, $5(71,4 \%)$, falta de pessoal, $1(14,3 \%)$ e divergência de conduta médica, $1(14,3 \%)$. A percentagem foi calculada sobre o total de citaçðes obtidas, 7 $(100,0 \%)$, uma vez que duas enfermeiras deram mais que uma resposta.

Mesmo entre as que responderam afirmativamente, $1(2,4 \%)$ enfermeira compleıou a resposta dizendo: “...não esıou completamente apta a dar assistência à puérpera levando em consideração as suas necessidades emocionais e gostaria de contar com mais subsidios para poder interceder".

Quanto à solicitação de enumerar as açôes de enfermagem para a assistência adequada às puérperas, $4(9,2 \%)$ enfermeiras não responderam sendo que as outras enfermeiras apenas relatam a diretriz para elaborar um plano e não o planejamento da assistência propriamente dita.

Para tanto os comentários sobre a questão n: 6 do Anexo serão feitas com base nas respostas das enfermeiras. Chama a atenção a resposta "o plano de enfermagem deve conter orientaçðes pré-determinadas" referida $12(28,6 \%)$ vezes; esta resposta não leva em consideração a individualidade da puérpera. Por sua vez, a resposta "a puérpera deve ser orientada durante a gestação nos serviços de pré-natal e cursos para gestantes" citada $7(16,7 \%$ ) vezes merece destaque, pois, embora PETROWISKI" afirme que o último trimestre da gravidez é o periodo ideal de preparo da gestante para as experiências que enfrentará no pós-parto, isto não dispensa a enfermeira da responsabilidade da assistência global à mulher no período puerperal. Preocupa-nos o fato de que houve apenas uma referência $(2,4 \%)$ sobre a necessidade da familia ser incluida no plano de assitência; o pai, principalmente, deve ser preparado para as tarefas que envolvem o pós-parto, e esta orientação auxilia o casal a assumir o papel de pais (CARR \& WALTON ${ }^{4}$ ).

\section{CONCLUSŌES}

De acordo com os objetivos propostos no presente trabalho, foi possivel chegar às seguintes conclusðes.

As enfermeiras såo capazes de identificar algumas das manifestações de comportamento que evidenciam as reaçðes emocionais das puérperas, embora, em muitas ocasiōes, não façam distinção entre estas e as necessidades físicas; isto revela, possivelmente, a dificuldade de identificação dos aspectos psicossociais envolvidos na assistência de enfermagem. Em resumo, as enfermeiras deste estudo não estão, provavelmente, suficientemente alertadas para os aspectos psicológicos do comportamento das puérperas.

É necessário reforçar o conhecimento das açðes de enfermagem que devem ser desempenhadas pelas enfermeiras ao assistirem as puérperas, bem como a importân- 
cia da compreensão das reaçðes psicológicas das mesmas, nos cursos de graduação (curso geral e habilitação), na especialização em enfermagem obstétrica e nos programas de educação continuada para enfermeiras que estão atuando na área.

SILVA, I.A. Emotional reactions of woman in the postpartum. Rev. Esc. Enf. USP. Säo Paulo, Sào Paulo, 22(2):237-246, Aug. 1988.

The author intended to obtain information through the nurses's statements, if they are able to indentify behavior manifestations in the pastpartum that could indicate emotional reactions and if they feel prepared to assist adequatily the postpartum women, considering physical and emotional aspects.

UNITERMS: Obstetrical Nursing. Puerperium.

\section{REFERÊNCIAS BIBLIOGRÁFICAS}

1. BECKER, C. The postpartum period. What is reality? Can.Nurs. Ottawa, 76(11):24-7, Dec.1980.

2. BEINSTEIN, M. Depressåo puerperal-fatores etiológiços e profilaxia. Feminina, Săo Paulo, 10(5):388-92, maio 1982 .

3. CANELlA, P.R.B. Alteraçðes psicossomáticas no puerpério. Feminina, São Paulo, 8(9):689-93, set. 1980.

4. CARR, K.C. \& WALTON, V.E. Early posipartum discharge. JOGN Nurs., Philadelphia, 11(1): 29-30, Jan/Feb. 1982.

5. DEUSTSCH, H. Puerpério y lactância: primeiras relaciones con el ninò. In: La psicologia de la mujer. 4.ed. Buenos Aires, Losada, 1971, cap.8, p. 241-71.

6. INGALLS, A.J. \& SALERNO, M.C. The postpartum period. In: Maternal and child health nursing. Saint Louis, Mosby, 1971. cap. 15, p. 157-78.

7. KURCGANT, P. Educação continua: Necessidades sentidas e evidenciadas por enfermeiras e obstetrizes do Municipio de São Paulo, 1977, Såo Paulo, 1978. (Disscrtaçào de Mestrado - Escola de Enfermagem da USP).

8. MALDONADO, M.T.P. Psicologia da gravidez. 2.ed. Petrópolis, Vozes, 1977, 118p.

9. MERCER, R.T. The nurse and maternal tasks of early postpartum. M.C.N. Neu York, 6(5):341-5, Sept/Oct.198i.

10. NAISH, C. apud WIEDENBACK, E. Safeguard the mother's breasts. Am. J. Nurs, New York, 51(9):546-9. Sept. 1951.

11. PETROWISKI, D.D. Effectiveness of prenatal and posinatal instruction in postpartum care. JOGN Nurs., New York, 10(5):386-9, Sept/Oct. 1981.

12. RUBIN, R. Puerperal change. Nurs. Oullook, New York, 9(12):753-5, Dec. 1961

13. Basic maternal behavior. Nurs. Outlook, New York, 9(11):683-6, Nov. 1961.

14. SHEEHAN, F. Assessing postpartum adjusıment: a pilol sludy. JOGN Nurs., Philadelphia, 10(1): 19-23, Jan/Feb. 1981.

15. WIEDENBACK, E. Safeguard the mother's breast. Am. J. Nurs., New York, 51(9):544-8 Sept. 1951.

Recebido para publicaçåo em 26/03/87

Aprovado para publicaçào em 9/6/88. 


\section{ANEXO \\ FORMULÁRIO}

\section{DESCRIÇÃO DA PERGUNTA}

1. Dados gerais

2. Hospital

3. Nome

4. Cargo que exerce

5. Tempo (em anos) que presta assistência à puérpera

6. Qualificação profissional:

Obstetriz

Enfermeira Obstétrica

7. Tipo de cuidado que presta à puérpera:

direto

indireto

II. Manifestaçð̃es de comportamento que evidenciam reaçðes emocionais de puérperas identificadas pelas enfermeiras.

Segundo alguns autores, a puérpera apresenta fases distintas de reaçðes emocionais que podem ser observadas pelos profissionais da equipe obstétrica e que podem servir de base na elaboração do plano de cuidados de enfermagem prestado às mesmas. Baseadas nessa teoria, gostariamos de saber:

1. Liste as manifestaçðes de comportamento que evidenciam reaçðes emocionais apresentadas pelas puérperas nas primeiras duas horas após o parto.

2. Liste as manifestaçð̃es de comportamento que evidenciam reaçðes emocionais apresentadas pelas puérperas no periodo de 2 a 72 horas após o parto.

3. Liste as manifestaçðes de comportamento que evidenciam reaçðes emocionais apresentadas pela puérperas após 72 horas.

4. A sra. julga-se preparada para dar atendimento adequado às puérperas com as manifestaçōes anteriormente descritas?

NÃO (passe para a questão n? 6)

SIM (passe para a questão n. 5)

5. O que poderia ser feito para ajudar a enfermeira a se preparar para prestar uma assistência de enfermagem às puérperas com as manifestaçōes relatadas pela senhora?

6. Qual o plano de assistência de enfermagem que a Sra. propõe para atender as puérperas com as manifestaçðes relatadas pela senhora? 